\title{
Genetic susceptibility to asbestos-related fibrotic pleuropulmonary changes
}

\author{
M.K. Kukkonen*, S. Hämäläinen*, S. Kaleva*, T. Vehmas*, M.S. Huuskonen*, \\ P. Oksa*, H. Vainio*, P. Piirilä ${ }^{*}$ and A. Hirvonen*
}

ABSTRACT: The objective of this study was to determine whether genetic polymorphisms in enzymes that metabolise oxidative agents modify the individual susceptibility to developing asbestos and smoking-related pleuropulmonary changes.

Nine polymorphisms of six genes (EPHX1, GSTM1, GSTM3, GSTP1, GSTT1 and NAT2) were genotyped from 1,008 Finnish asbestos-exposed workers. The genotype data were compared to signs of lung fibrosis and pleural thickenings, as well as with total lung capacity, single-breath diffusing capacity of the lung for carbon monoxide $(D L, C O)$ and specific diffusing capacity (expressed as DL,Co per unit of alveolar volume (VA)).

The GSTT1 deletion polymorphism was associated with fibrotic changes $(p=0.003)$, and decreased $D L, C O(p=0.02)$ and $D L, C O / V A(p=0.002)$, and the GSTM1 deletion polymorphism was associated with the greatest thickness of pleural plaques $(p=0.009)$. On further analysis, the GSTT1 null genotype was found to pose over a three-fold risk for severe fibrotic changes (OR 3.12, 95\% $\mathrm{Cl} 1.51-6.43)$, and around two-fold risks for decreased $D$ L,CO (OR 1.77, 95\% Cl 1.06-2.95) and DL,CO/VA (OR 2.37, 95\% CI 1.33-4.23). In addition, the GSTM1 null genotype showed an elevated risk (OR 1.36, 95\% $\mathrm{Cl} 1.03-1.80)$ for thicker pleural plaques.

Our data suggest that inherited detoxification capacity may affect the development and severity of asbestos and smoking-related nonmalignant pulmonary changes.

KEYWORDS: Asbestos, fibrosis, pleural plaques, polymorphism, xenobiotic-metabolising enzyme

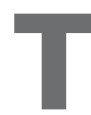

he adverse pulmonary effects of asbestos exposure are well characterised; it has been shown to cause lung cancer and mesothelioma, as well as nonmalignant pulmonary and pleural disorders. Although the exact mechanism by which inhalation of asbestos fibres leads to lung tissue injury is still unclear, it may involve a persistent inflammatory response mediated by reactive oxygen species, cytokines and pro-inflammatory factors [1, 2]. Currently, it is believed that individual susceptibility to asbestos and smokingrelated pulmonary diseases is modified by genetic polymorphisms of enzymes that metabolise oxidative agents.

Interstitial lung fibrosis, also called asbestosis, is caused by the deposition of asbestos fibres in the lungs. Asbestosis is characterised by shortness of breath and cough, and it is known to be associated with restrictive lung function impairment and impairment of gas exchange properties of lung parenchyma measured as decreased diffusing capacity of the lung for carbon monoxide $(D L, C O)[3]$.
Other lesions induced by asbestos are pleural plaques, circumscribed thickenings of the pleura that may calcify over long periods of time. However, pleural thickenings unrelated to asbestos exposure are also very common [4].

Both environmental and genetic factors are believed to participate in the development of asbestosis. Yet, a very limited number of reports have discussed the potential genetic background of asbestos-induced nonmalignant pulmonary diseases, such as lung fibrosis and pleural studies have been contradictory.

Glutathione S-transferases (GSTs) are a superfamily of xenobiotic-metabolising enzymes (XMEs) involved in conjugation of glutathione with various electrophilic compounds and products of oxidative stress. A widely studied member of the family, GSTM1, is involved in the metabolism of diol-epoxide derivatives of polycyclic aromatic hydrocarbons (PAHs) and reactive oxygen species. GSTT1, however, can plaques [5]. In addition, the findings of these
AFFILIATIONS

*Finnish Institute of Occupational Health, and

"Dept of Clinical Physiology, Helsinki University Hospital, Helsinki, Finland.

CORRESPONDENCE

A. Hirvonen

Finnish Institute of Occupational

Health

Topeliuksenkatu 41 a A

FIN-00250 Helsinki

Finland

E-mail: ari.hirvonen@ttl.fi

Received:

March 292010

Accepted after revision:

Sept 072010

First published online:

Sept 162010 
detoxify methylating agents, pesticides and many chemicals present in cigarette smoke [6]. The GSTP1 enzyme, which is the most abundantly expressed GST in human lungs, shares some substrate specificity with GSTM1 and is active towards many epoxides of PAHs, including benzo(a)pyrene [7].

The GSTM1 null genotype (gene deficiency) is one of the proposed risk factors for asbestos induced nonmalignant pulmonary diseases [8]. Conversely, the GSTT1 null genotype has been suggested as a protective factor against the development of asbestosis [9]. In addition to GSTM1 and GSTT1, the GSTP1 genotype has been associated with asbestos-related pulmonary fibrosis [10]. However, subsequent studies have not confirmed these findings [11-13].

$\mathrm{N}$-Acetyltransferases (NATs) are involved in the metabolism of various xenobiotics including the aromatic and heterocyclic amines present in tobacco smoke and the diet [14, 15]. We have previously found an association between the NAT2 slowacetylator genotype, and increased risk for both malignant (mesothelioma) and nonmalignant (asbestosis and pleural plaques) pulmonary disorders among asbestos-exposed workers $[16,17]$. In a subsequent study, however, the NAT2 slowacetylator genotypes were associated with decreased risk of mesothelioma in an Italian study population [18]. Moreover, the low-activity genotypes of microsomal epoxide hydrolase (EPHX1), a critical biotransformation enzyme that plays a dual role in the activation and detoxification of exogenous chemicals, such as epoxides and PAHs [19], were positively associated with malignant mesothelioma in the Italian study population while they were negatively associated with this malignancy in the Finnish study population [18].

We aimed to further investigate the potential genetic risk factors for pulmonary fibrosis and other asbestos-induced nonmalignant lesions among 1,008 Finnish Caucasian asbestosexposed workers. Based on previous association studies, seven polymorphisms were chosen to be analysed from the five aforementioned XME genes (GSTM1, GSTT1, GSTP1, EPHX1 and NAT2). In addition, two relevant functional polymorphisms were analysed from the GSTM3 gene, another important member of the GST family [20, 21].

\section{METHODS}

\section{Study population}

This study combined data from two previous screening studies that aimed to detect early occupational chest diseases among asbestos-exposed workers. The first study group $(n=602)$ was recruited in 1996-1997 and consisted of asbestos-exposed subjects who lived in the Helsinki (Finland) area, and had an asbestos-related occupational disease and a smoking history $[22,23]$. The second study group $(n=633)$ was recruited in 2003-2004, and consisted of asbestos-exposed persons from three geographic areas (Helsinki, Tampere and Turku, Finland) who were heavily exposed, had previously been diagnosed with asbestos-related occupational disease, or had visited occupational medicine clinics in Helsinki and Tampere for clinical follow-up [24].

Altogether, 178 of the subjects recruited in 2003-2004 had already participated in the first study conducted in 1996-1997. Therefore, they were excluded from the second patient group in the present study before combining the data. In the combined study population, blood samples were available for 1,021 subjects, in 1,013 of whom genotyping was successful. However, five more subjects were excluded because of missing background information. Thus, the final study group consisted of 1,008 subjects (992 males and 16 females).

In order to see whether the genotype frequencies in the case group were similar to those in the general Finnish population, a demographic reference group consisting of 2,155 Finnish Caucasians recruited from south-western Finland was also included in the study. The recruitment of the referents has been described in detail previously [25]. For this study, 49 control subjects were excluded because they had been diagnosed with some form of malignant disease and one because of missing background information. Thus, the final demographic reference group consisted of 2,105 subjects $(1,051$ males and 1,054 females). Unfortunately, since neither asbestos exposure history nor clinical data were available for them and detailed data on smoking was obtained only from the current smokers, this group could only be used as demographic referents and not as a reference group in statistical analyses.

Approval for the study was obtained from the local ethics committee (Ethics Committee of the Finnish Institute of Occupational Health, Helsinki, Finland) according to the legislation at the time of the original study. All subjects gave their informed consent to participate in the study.

\section{Radiological examinations}

The lungs of the study subjects were imaged with the subject prone and in full inspiration with four different scanners: in 1996-1997, the Picker PO 2000 (Picker International, Cleveland, $\mathrm{OH}, \mathrm{USA}$ ) device was used for both high-resolution computed tomography (HRCT) and spiral computed tomography (CT) scanning of the lungs; in 2003-2004, the patients were HRCTscanned with a Siemens Somatom Balance (Siemens Medical, Erlangen, Germany) in Helsinki, a Siemens Somatom Plus 4 (Siemens Medical) in Tampere and a GE Light-Speed 16 Advantage (GE Healthcare, Milwaukee, WI, USA) in Turku; in 2003-2004, the patients with high cancer risk were also imaged with spiral CT. The HRCT images were printed as hard copies and analysed blindly by two (2003-2004) or three (1996-1997) radiologists.

The radiologists scored the signs of fibrosis visually using an arbitrary semiquantitative scale from 0 to $\mathrm{V}$ including one subclass between each class. Several signs of pleural changes were also recorded: the extent (in square centimetres), and greatest thickness of pleural thickenings (International Labour Organization "width" 0: no plaques; $1: \leqslant 5 \mathrm{~mm} ; 2: 5-10 \mathrm{~mm} ; 3$ : $\geqslant 10 \mathrm{~mm}$ ) and their degree of calcification (0: none; 1 : sparse; 2 : a considerable part of the pleural thickenings; 3: nearly all). More detailed methods, including intra- and inter-reader consistencies, have been reported previously [22].

\section{Lung function examinations}

Single-breath $D \mathrm{~L}, \mathrm{CO}$, specific diffusing capacity (expressed as $D \mathrm{~L}, \mathrm{CO}$ per unit of alveolar volume $(\mathrm{VA}))$, and total lung capacity (TLC) were measured by the helium single-breath dilution method using a Masterlab Transfer or a Compact Lab Transfer device (Erich Jaeger, Würzburg, Germany) according to European Respiratory Society recommendations [26]. Correction of DL,CO 
was performed according to the patient's actual haemoglobin levels. The lung function variables were handled as percentages of the reference values of VILJANEN [27], based on the distribution of values in the reference population. $D \mathrm{~L}, \mathrm{CO}$ or $\mathrm{DL}, \mathrm{CO} / V \mathrm{~A}$ $<74 \%$ predicted, and TLC $<80 \%$ pred were considered to be decreased [27].

\section{Genotyping analyses}

DNA was extracted mechanically (KingFisher mL; Thermo, Erembodegem, Belgium) from whole blood using the Biosprint 15 DNA Blood Kit (Qiagen, Hilden, Germany) and stored at $-20^{\circ} \mathrm{C}$ until use.

The presence or absence of GSTM1 and GSTT1 genes was detected by using a multiplex PCR method [28]. The 3-bp deletion of the GSTM3 gene (rs1799735), the GSTP1 exon 5 genotype (Ile105Val, rs1695) and the EPHX1 exon 4 genotype (His139Arg, rs2234922) were detected using PCR-based restriction fragment length polymorphism methods [20, 29, 30]. The GSTM3 promoter area genotype (rs1332018), EPHX1 exon 3 genotype (Tyr113His, rs1051740) and two NAT2 genotypes (C282T, rs1041983 and T341C, rs45532639) were detected using TaqMan allelic discrimination assays [21, 31, 32].

The two NAT2 polymorphisms studied are considered sufficient for reliable prediction of the NAT2 phenotype in Caucasian populations [33]. Consequently, the subjects were categorised to fast and slow NAT2 acetylators according to the number of wild-type and variant alleles in these two polymorphic loci: subjects with two variant alleles were considered slow acetylators and all others were included in the fast acetylator category [34]. Similarly, the EPHX1 diplotypes were categorised into putative phenotype groups (high, intermediate, low and very low activity) essentially as done by BENHAMOU et al. [35].

For quality control, two independent readers interpreted the results and a random selection of $10 \%$ of all samples was retested. No discrepancies were discovered in the replicate tests.

\section{Statistical analysis}

The associations between genotypes, fibrosis, pleural plaques and lung function parameters (TLC, DL,CO and $D \mathrm{~L}, \mathrm{CO} / V \mathrm{~A}$ ) were evaluated by using linear regression analysis. Logistic regression analysis was used to further study the risk for lung function impairment, fibrotic changes, pleural plaques and their severity with a particular genotype. Covariates used in the analysis were: sex, age, smoking exposure in pack-years and asbestos exposure in years for fibrosis; and sex, age, smoking and asbestos exposure, and forced expiratory volume in $1 \mathrm{~s}$ for TLC, DL,CO and DL,CO/VA. Occasionally, missing covariate data was replaced with the group mean value (47 replacements for asbestos exposure and 20 replacements for smoking exposure). All of the data analyses were performed using SPSS version 15.0 (SPSS Inc., Chicago, IL, USA).

Our study $(n=1,008)$ had $80 \%$ power to detect odds ratios (ORs) from 1.54 to 1.80 depending on the minor allele frequency (13-46\%). After stratifying the subjects according to radiological signs, the OR detected with $80 \%$ power ranged from 1.55 to 1.81 (mild changes; $\mathrm{n}=917$ ) and from 2.02 to 2.42 (severe changes; $n=313$ ). The calculations are based on a twosided $\alpha$ of 0.05 .
Chi-squared analysis was used to test for a deviation from Hardy-Weinberg equilibrium (HWE). Since our study is a case-only study, HWE was only calculated for the demographic referents; it is expected that HWE is distorted in the case sample in the region of association [36].

\section{RESULTS}

The demographics and HRCT characteristics of the asbestosexposed workers are summarised in table 1.

The genotype and phenotype frequencies of the studied polymorphisms in the asbestos-exposed workers were similar to those in the demographic referents (supplementary table 1), among whom, all the studied polymorphisms were in HWE (data not shown).

The fibrosis score was found to be associated with the GSTT1 deletion polymorphism $(\mathrm{p}=0.003)$ and the greatest thickness of pleural plaques with the GSTM1 deletion polymorphism $(p=0.009)$ (table 2). In addition, tendencies, although failing to reach statistical significance, were detected between the GSTM1 deletion polymorphism and the extent of pleural plaques $(p=0.071)$ and GSTP1 Ile105Val polymorphism and the calcification of plaques $(\mathrm{p}=0.080)$. Moreover, $D \mathrm{~L}, \mathrm{CO}$ and $D L, C O / V A$ values were found to be associated with the GSTT1 deletion polymorphism $(\mathrm{p}=0.021$ and $\mathrm{p}=0.002$, respectively) and NAT2 C282T polymorphism (rs1041983) $(\mathrm{p}=0.007$ and $p=0.006$, respectively) (table 3 ). Tendencies were also seen between the GSTM3 promoter area polymorphism (rs1332018) $(\mathrm{p}=0.098)$ and NAT2 T341C polymorphism (rs45532639) $(\mathrm{p}=0.076)$, and $D \mathrm{~L}, \mathrm{CO} / V \mathrm{~A}$.

The observed significant associations were further analysed by stratifying the cases according to the existence and severity of

TABLE 1 Characteristics of the 1,008 asbestos-exposed
Workers

Data are presented as mean \pm SD or $n(\%) . \%$ pred: \% predicted; TLC: total lung capacity; $D L, C O$ : diffusing capacity of the lung for carbon monoxide; VA: alveolar volume. ${ }^{\#}: \mathrm{n}=988 ;{ }^{\bullet}: \mathrm{n}=943{ }^{+}: \mathrm{n}=775 ;{ }^{\text {s. }} \mathrm{n}=1,006 ;{ }^{f}: \mathrm{n}=1,004 ;{ }^{\# \#}: \mathrm{n}=977$; "थ: $n=958 ;{ }^{++}: n=963 ;{ }^{\S \S}: n=965$. 


\begin{tabular}{|c|c|c|c|c|}
\hline \multirow{2}{*}{$\begin{array}{l}\text { TABLE } 2 \\
\text { Phenotype }\end{array}$} & \multicolumn{4}{|c|}{$\begin{array}{l}\text { Association between genetic polymorphisms } \\
\text { and pleural plaques }\end{array}$} \\
\hline & Gene & Polymorphism & $\beta^{\#}$ & p-value \\
\hline \multirow[t]{11}{*}{ Fibrosis } & GSTT1 & Deletion & -0.09 & 0.003 \\
\hline & GSTM1 & Deletion & -0.024 & 0.431 \\
\hline & GSTM3 & rs1799735 & -0.30 & 0.329 \\
\hline & & rs1332018 & 0.005 & 0.180 \\
\hline & GSTP1 & rs1695 & 0.002 & 0.937 \\
\hline & $E P H X 1$ & rs1051740 & -0.025 & 0.410 \\
\hline & & rs2234922 & -0.014 & 0.656 \\
\hline & & Putative phenotype & 0.017 & 0.571 \\
\hline & NAT2 & rs1041983 & 0.001 & 0.962 \\
\hline & & rs45532639 & -0.046 & 0.130 \\
\hline & & Acetylator status & 0.043 & 0.153 \\
\hline \multicolumn{5}{|l|}{ Pleural plaques } \\
\hline \multirow[t]{11}{*}{ Greatest thickness } & GSTT1 & Deletion & 0.016 & 0.604 \\
\hline & GSTM1 & Deletion & -0.008 & 0.009 \\
\hline & GSTM3 & rs1799735 & 0.008 & 0.802 \\
\hline & & rs1332018 & 0.004 & 0.890 \\
\hline & GSTP1 & rs1695 & -0.003 & 0.912 \\
\hline & EPHX1 & rs1051740 & -0.013 & 0.676 \\
\hline & & rs2234922 & -0.004 & 0.903 \\
\hline & & Putative phenotype & 0.010 & 0.750 \\
\hline & NAT2 & rs1041983 & -0.22 & 0.454 \\
\hline & & rs45532639 & -0.006 & 0.850 \\
\hline & & Acetylator status & 0.039 & 0.189 \\
\hline \multirow[t]{11}{*}{ Extent } & GSTT1 & Deletion & 0.017 & 0.588 \\
\hline & GSTM1 & Deletion & -0.055 & 0.071 \\
\hline & GSTM3 & rs1799735 & 0.021 & 0.481 \\
\hline & & rs1332018 & -0.001 & 0.962 \\
\hline & GSTP1 & rs1695 & 0.020 & 0.519 \\
\hline & $E P H X 1$ & rs1051740 & -0.018 & 0.547 \\
\hline & & rs2234922 & -0.034 & 0.268 \\
\hline & & Putative phenotype & -0.004 & 0.900 \\
\hline & NAT2 & rs 1041983 & -0.43 & 0.157 \\
\hline & & rs45532639 & 0.005 & 0.858 \\
\hline & & Acetylator status & 0.041 & 0.178 \\
\hline \multirow[t]{11}{*}{ Calcification } & GSTT1 & Deletion & 0.042 & 0.146 \\
\hline & GSTM1 & Deletion & -0.016 & 0.573 \\
\hline & GSTM3 & rs1799735 & -0.029 & 0.316 \\
\hline & & rs1332018 & 0.019 & 0.516 \\
\hline & GSTP1 & rs1695 & 0.051 & 0.080 \\
\hline & $E P H X 1$ & rs1051740 & -0.016 & 0.591 \\
\hline & & rs2234922 & -0.002 & 0.943 \\
\hline & & Putative phenotype & 0.011 & 0.706 \\
\hline & NAT2 & rs1041983 & -0.037 & 0.199 \\
\hline & & rs45532639 & 0.043 & 0.136 \\
\hline & & Acetylator status & -0.009 & 0.769 \\
\hline
\end{tabular}

Covariates used in the analysis: sex, age, smoking exposure in pack-years and asbestos exposure in years. ${ }^{\#}$ : standardised coefficient.

radiological signs and pulmonary diffusing capacity. The signs of fibrosis were considered mild if the radiological score was $<2$ and severe if the score was $\geqslant 2$. The greatest thickness of pleural plaques was categorised as $<5$ or $\geqslant 5 \mathrm{~mm}$ and their extent as $\leqslant 100$ or $>100 \mathrm{~cm}^{2}$.

\begin{tabular}{|c|c|c|c|c|}
\hline Phenotype & Gene & Polymorphism & $\beta^{\#}$ & p-value \\
\hline \multirow[t]{11}{*}{ TLC \% pred } & GSTT1 & Deletion & 0.027 & 0.421 \\
\hline & GSTM1 & Deletion & 0.036 & 0.851 \\
\hline & GSTM3 & rs1799735 & 0.007 & 0.585 \\
\hline & & rs1332018 & 0.024 & 0.126 \\
\hline & GSTP1 & rs1695 & -0.025 & 0.146 \\
\hline & EPHX1 & rs1051740 & 0.032 & 0.947 \\
\hline & & rs2234922 & 0.010 & 0.765 \\
\hline & & Putative phenotype & -0.025 & 0.826 \\
\hline & NAT2 & rs1041983 & 0.028 & 0.256 \\
\hline & & rs45532639 & -0.015 & 0.111 \\
\hline & & Acetylator status & 0.003 & 0.314 \\
\hline \multirow{12}{*}{$\begin{array}{l}\text { Single-breath } \\
\text { DL,Co \% pred }\end{array}$} & GSTT1 & Deletion & 0.062 & 0.021 \\
\hline & & & & \\
\hline & GSTM1 & Deletion & 0.010 & 0.971 \\
\hline & GSTM3 & rs1799735 & 0.052 & 0.221 \\
\hline & & rs1332018 & -0.039 & 0.383 \\
\hline & GSTP1 & rs1695 & 0.012 & 0.948 \\
\hline & EPHX1 & rs1051740 & 0.047 & 0.616 \\
\hline & & rs2234922 & 0.032 & 0.525 \\
\hline & & Putative phenotype & -0.018 & 0.974 \\
\hline & NAT2 & rs1041983 & -0.075 & 0.007 \\
\hline & & rs45532639 & 0.062 & 0.132 \\
\hline & & Acetylator status & 0.007 & 0.319 \\
\hline \multirow[t]{11}{*}{$D \mathrm{~L}, \mathrm{CO} / \mathrm{VA}_{\mathrm{A}} \%$ pred } & GSTT1 & Deletion & 0.095 & 0.002 \\
\hline & GSTM1 & Deletion & -0.013 & 0.650 \\
\hline & GSTM3 & rs1799735 & 0.017 & 0.585 \\
\hline & & rs1332018 & -0.053 & 0.098 \\
\hline & GSTP1 & rs1695 & 0.035 & 0.243 \\
\hline & EPHX1 & rs1051740 & 0.047 & 0.171 \\
\hline & & rs2234922 & 0.022 & 0.529 \\
\hline & & Putative phenotype & -0.022 & 0.540 \\
\hline & NAT2 & rs1041983 & -0.086 & 0.006 \\
\hline & & rs45532639 & -0.057 & 0.076 \\
\hline & & Acetylator status & 0.013 & 0.647 \\
\hline
\end{tabular}

Covariates used in the analysis: sex, age, smoking exposure in pack-years, asbestos exposure in years and forced expiratory volume in $1 \mathrm{~s}$. TLC: total lung capacity; \% pred: \% predicted; DL,CO: diffusing capacity of the lung for carbon

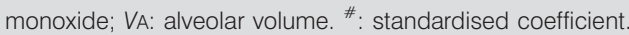

In the stratified analysis, the GSTT1 null genotype was found to pose a three-fold higher risk for severe fibrotic changes (OR 3.12, 95\% CI 1.51-6.43) (table 4). Similarly, the GSTM1 null genotype was found to slightly elevate the risk for $\geqslant 5$-mm thick pleural plaques (OR 1.36, 95\% CI 1.03-1.80) as well as the extent $\left(\geqslant 100 \mathrm{~cm}^{2}\right)$ of plaques (OR 1.27, 95\% CI 0.98-1.65), although the latter association was only of borderline statistical significance (table 5). The GSTT1 deletion was also found to pose a 1.8-fold greater risk (OR 1.77, 95\% CI 1.06-2.95) for decreased DL,CO and 2.4-fold higher risk (OR 2.37, 95\% CI 1.33-4.23) for decreased $D \mathrm{~L}, \mathrm{CO} / V \mathrm{~A}$ (table 6). When only subjects with fibrotic changes were considered, the risk for lower pulmonary diffusing capacity was somewhat higher (OR 1.88 (95\% CI 1.10-3.21) for $D \mathrm{~L}, \mathrm{CO}$ and 2.81 (1.55-5.12) for $D \mathrm{~L}, \mathrm{CO} / \mathrm{VA}$; data not shown). 


\begin{tabular}{|c|c|c|c|c|c|c|c|}
\hline GSTT1 & \multicolumn{7}{|c|}{ Fibrosis } \\
\hline Present & 198 (89.2) & 681 (86.6) & 1.0 & 611 (87.9) & 1.0 & 70 (76.9) & 1.0 \\
\hline
\end{tabular}

The associations between polymorphisms and pulmonary changes were also studied separately in the two original study populations (supplementary tables 2 and 3 ). The only association that showed statistical significance in both the subcohorts was between GSTT1 deletion and fibrotic changes. Moreover, when the other significant findings were further analysed after stratifying the cases according to the existence and severity of radiologic signs and pulmonary diffusing capacity, the only statistically significant associations were between GSTT1 deletion and both DL,CO and DL,CO/VA in the first (19961997) study population (data not shown).

When the potential gene-gene interactions were studied, no significant combined effects were seen for any of the studied genotype combinations.

\section{DISCUSSION}

Our study is the first to demonstrate a significant association between the GSTT1 null genotype and severe fibrotic changes of the lungs confirmed by HRCT. This association was observed both in the whole study population and independently in both the studied subcohorts. The previous studies have suggested a protective, if any, role for GSTT1 deletion against the development of asbestosis $[9,12,13]$.

We also found an association between the GSTT1 null genotype, and low $D \mathrm{~L}, \mathrm{CO}$ and $D \mathrm{~L}, \mathrm{CO} / V \mathrm{~A}$. Since decreased diffusing capacity is characteristic of asbestosis, due to fibrotic processes of the lung parenchyma, this finding could simply reflect the correlation that was found between fibrosis and GSTT1. However, the association was seen in the whole study group, not just among the workers with fibrotic changes. Therefore, this observation supports our finding suggesting an association between the GSTT1 genotype and development of lung fibrosis. In addition, a novel association between the GSTM1 deletion and pleural plaques was detected; previously, the GSTM1 null genotype has been proposed as a risk factor for asbestos-related parenchymal, rather than pleural, disease [8].

The GSTP1 genotype has also been associated with risk of developing asbestosis [10]. We did not, however, find any statistically significant associations between GSTP1 polymorphism and nonmalignant pulmonary changes.

Although our findings contrast with previous studies, they are consistent with the functional consequences of the associated polymorphisms: deletion of an XME gene is presumed to lead to decreased detoxification capacity and thereby to accumulation of oxidative agents. Oxidative stress, in turn, may lead to lung tissue injury and development of pulmonary disorders.

There are several potential explanations for the discordance between the outcomes of the present and previous studies. First, the sampling of the patients and controls varies considerably. In addition, the inclusion criteria are very heterogeneous; some studies have used a strict diagnosis of asbestosis, while others have studied various indicators of parenchymal and pleural disease independently.

Another major difference between the present and previous research frameworks is the sample size; our study population comprised $>1,000$ asbestos-exposed workers, of whom almost 800 showed degrees of fibrosis. In earlier studies, the number of fibrotic patients has been much smaller, varying from tens to hundreds. Consequently, the elevated risk that was detected only for severe changes in the present study could have been

TABLE 5 Distribution of GSTM1 genotypes according to the existence and severity of radiological changes

GSTM1

\begin{tabular}{|c|c|c|c|c|c|c|}
\hline & $<5 \mathrm{~mm}^{\#}$ & $\geqslant 5 \mathrm{~mm}$ & OR $(95 \% \mathrm{CI})^{\circ}$ & $<100 \mathrm{~cm}^{2 \#}$ & $\geqslant 100 \mathrm{~cm}^{2}$ & OR $(95 \% \mathrm{Cl})$ \\
\hline Present & $181(58.2)$ & $353(50.8)$ & 1.0 & $323(55.6)$ & $210(49.6)$ & 1.0 \\
\hline Null & $130(41.8)$ & 342 (49.2) & $1.36(1.03-1.80)$ & $258(44.4)$ & $213(50.4)$ & $1.27(0.98-1.65$ \\
\hline
\end{tabular}

Data are presented as $n(\%)$, unless otherwise stated. ${ }^{\#}:$ reference category; ${ }^{\bullet}$ : adjusted for age, sex, smoking exposure in pack-years and asbestos exposure in years. 


\section{TABLE 6 Distribution of GSTT1 genotypes according to pulmonary diffusing capacity}

\begin{tabular}{|c|c|c|c|c|c|c|}
\hline GSTT1 & \multicolumn{6}{|c|}{ Diffusing capacity } \\
\hline Present & $145(81.9)$ & $686(87.8)$ & 1.0 & $72(77.4)$ & 761 (87.8) & 1.0 \\
\hline Null & $32(18.1)$ & 95 (12.2) & $1.77(1.06-2.95)$ & $21(22.6)$ & $106(12.2)$ & $2.37(1.33-4.23)$ \\
\hline
\end{tabular}

left unrecognised in the previous studies with much smaller sample sizes, where stratification was not appropriate.

We have previously found an association between the NAT2 slow-acetylator genotype and both malignant and nonmalignant pulmonary disorders among asbestos-exposed workers $[16,17]$. The risk for nonmalignant disorders was over fourfold higher for patients with a combination of a NAT2 slowacetylator genotype and the GSTM1 null genotype. Unfortunately, we could not confirm this finding in the present study. This could be due to the different inclusion criteria for cases: in the previous study, all nonmalignant disorders were grouped together, while in the current study, fibrotic changes and pleural plaques were studied separately. In addition, the discrepancy could be partly explained by the exposure level of the subjects: in our earlier study, the workers were all heavily exposed to asbestos and the exposure was confirmed with a lung-fibre burden measurement. In the present study, the workers were exposed to various levels of asbestos and no fibre measurements were performed. The sample size was also remarkably smaller in our earlier study.

Our study also has potential limitations: the patients were enrolled in three cities over two separate primary studies; four different CT scanners were used; and seven radiologists participated in the image reading. However, since the Finnish population is very homogenous and the three big cities where the patients were enrolled are all located in southern Finland very near to each other, we do not believe that geographic origin at the time of the examination has caused any significant bias in the data analysis. Moreover, any inconsistency in image reading adds inaccuracy and, thus, random noise to the results, leading to a loss of power rather than systematic error. This increases the error variance in computations and the detected associations are, therefore, likely to be underestimated.

Due to the multiple comparisons performed, false-positive associations may have been observed. Most of the methods correcting for multiple testing are very conservative and it is not clear, for example, for how many comparisons one should adjust [37]. Based on previous findings, we had an a priori hypothesis for each polymorphism chosen, which reduces the need for correction. However, these results should be considered with caution until replicated in another study population.
In summary, our results suggest that the GSTT1 deletion is associated with severe pulmonary fibrosis. Additionally, the GSTM1 deletion may have a role in the development of pleural plaques. These observations suggest that polymorphisms in XME genes may indeed be involved in the development of asbestos-induced nonmalignant pulmonary diseases and their severity. This information may be of great value for the ongoing efforts against asbestos-associated disorders; due to the long latency period between asbestos exposure and the disease, there are still a great number of people in the working population who have been exposed previously and are currently at risk of lung changes.

\section{SUPPORT STATEMENT}

This study was supported by the Finnish Work Environment Fund (grant 105091). In addition, P. Piirilä has received grants from the Finnish Foundation Against Tuberculosis and from the Ida Montin Foundation in 2008 for studies on occupational asthma.

\section{STATEMENT OF INTEREST}

None declared.

\section{ACKNOWLEDGEMENTS}

The authors thank S. Hyttinen (Finnish Institute of Occupational Health, Helsinki, Finland) for the assistance with genotyping and sample management, P. Toivio (Finnish Institute of Occupational Health, Tampere, Finland) for help with data handling and A. Voho (Finnish Institute of Occupational Health, Helsinki, Finland) for her valuable advice.

\section{REFERENCES}

1 Manning CB, Vallyathan V, Mossman BT. Diseases caused by asbestos: mechanisms of injury and disease development. Int Immunopharmacol 2002; 2: 191-200.

2 Mossman BT, Gee JB. Asbestos-related diseases. N Engl J Med 1989; 320: 1721-1730.

3 Miller A, Lilis R, Godbold J, et al. Relationship of pulmonary function to radiographic interstitial fibrosis in 2,611 long-term asbestos insulators. An assessment of the International Labour Office profusion score. Am Rev Respir Dis 1992; 145: 263-270.

4 Cugell DW, Kamp DW. Asbestos and the pleura: a review. Chest 2004; 125: 1103-1117.

5 Neri M, Ugolini D, Dianzani I, et al. Genetic susceptibility to malignant pleural mesothelioma and other asbestos-associated diseases. Mutat Res 2008; 659: 126-136.

6 Guengerich FP, Thier R, Persmark M, et al. Conjugation of carcinogens by theta class glutathione $S$-transferases: mechanisms 
and relevance to variations in human risk. Pharmacogenetics 1995; 5: S103-S107.

7 Hayes JD, Pulford DJ. The glutathione S-transferase supergene family: regulation of GST and the contribution of the isoenzymes to cancer chemoprotection and drug resistance. Crit Rev Biochem Mol Biol 1995; 30: 445-600.

8 Smith CM, Kelsey KT, Wiencke JK, et al. Inherited glutathione-Stransferase deficiency is a risk factor for pulmonary asbestosis. Cancer Epidemiol Biomarkers Prev 1994; 3: 471-477.

9 Franko A, Dodic-Fikfak M, Arneric N, et al. Glutathione Stransferases GSTM1 and GSTT1 polymorphisms and asbestosis. J Occup Environ Med 2007; 49: 667-671.

10 Franko A, Dolzan V, Arneric N, et al. The influence of genetic polymorphisms of GSTP1 on the development of asbestosis. J Occup Environ Med 2008; 50: 7-12.

11 Jakobsson K, Rannug A, Alexandrie AK, et al. Genetic polymorphism for glutathione- $S$-transferase $\mu$ in asbestos cement workers. Occup Environ Med 1994; 51: 812-816.

12 Jakobsson K, Rannug A, Alexandrie AK, et al. Radiographic changes and lung function in relation to activity of the glutathione transferases $\theta$ and $\mu$ among asbestos cement workers. Toxicol Lett 1995; 77: 363-369.

13 Kelsey KT, Nelson HH, Wiencke JK, et al. The glutathione $S$ transferase $\theta$ and $\mu$ deletion polymorphisms in asbestosis. Am J Ind Med 1997; 31: 274-279.

14 Hein DW, Doll MA, Rustan TD, et al. Metabolic activation and deactivation of arylamine carcinogens by recombinant human NAT1 and polymorphic NAT2 acetyltransferases. Carcinogenesis 1993; 14: 1633-1638.

15 Hein DW. Molecular genetics and function of NAT1 and NAT2: role in aromatic amine metabolism and carcinogenesis. Mutat Res 2002; 506-507: 65-77.

16 Hirvonen A, Pelin K, Tammilehto L, et al. Inherited GSTM1 and NAT2 defects as concurrent risk modifiers in asbestos-related human malignant mesothelioma. Cancer Res 1995; 55: 2981-2983.

17 Hirvonen A, Saarikoski ST, Linnainmaa K, et al. Glutathione Stransferase and $\mathrm{N}$-acetyltransferase genotypes and asbestosassociated pulmonary disorders. J Natl Cancer Inst 1996; 88: 1853-1856.

18 Neri M, Taioli E, Filiberti R, et al. Metabolic genotypes as modulators of asbestos-related pleural malignant mesothelioma risk: a comparison of Finnish and Italian populations. Int J Hyg Environ Health 2006; 209: 393-398.

19 Fretland AJ, Omiecinski CJ. Epoxide hydrolases: biochemistry and molecular biology. Chem Biol Interact 2000; 129: 41-59.

20 Inskip A, Elexperu-Camiruaga J, Buxton N, et al. Identification of polymorphism at the glutathione S-transferase, GSTM3 locus: evidence for linkage with GSTM1*A. Biochem J 1995; 312: 713-716.

21 Liu X, Campbell MR, Pittman GS, et al. Expression-based discovery of variation in the human glutathione S-transferase M3 promoter and functional analysis in a glioma cell line using allele-specific chromatin immunoprecipitation. Cancer Res 2005; 65: 99-104.

22 Huuskonen O, Kivisaari L, Zitting A, et al. High-resolution computed tomography classification of lung fibrosis for patients with asbestos-related disease. Scand J Work Environ Health 2001; 27: 106-112.

23 Tiitola M, Kivisaari L, Zitting A, et al. Computed tomography of asbestos-related pleural abnormalities. Int Arch Occup Environ Health 2002; 75: 224-228.

24 Vierikko T, Järvenpää R, Autti $\mathrm{T}$, et al. Chest CT screening of asbestos-exposed workers: lung lesions and incidental findings. Eur Respir J 2007; 29: 78-84.

25 Voho A, Impivaara O, Jarvisalo J, et al. Distribution of glutathione Stransferase M1, P1 and T1 genotypes in different age-groups of Finns without diagnosed cancer. Cancer Detect Prev 2006; 30: 144-151.

26 Cotes JE, Chinn DJ, Quanjer PH, et al. Standardization of the measurement of transfer factor (diffusing capacity). Report Working Party Standardization of Lung Function Tests, European Community for Steel and Coal. Official Statement of the European Respiratory Society. Eur Respir J 1993; 6: Suppl. 16, 41-52.

27 Viljanen AA. Reference values for spirometric, pulmonary diffusing capacity and body plethysmographic studies. Scand J Clin Invest 1982; 42: Suppl. 159, 1-50.

28 Jourenkova-Mironova N, Voho A, Bouchardy C, et al. Glutathione S-transferase GSTM1, GSTM3, GSTP1 and GSTT1 genotypes and the risk of smoking-related oral and pharyngeal cancers. Int $J$ Cancer 1999; 81: 44-48.

29 Saarikoski ST, Voho A, Reinikainen M, et al. Combined effect of polymorphic GST genes on individual susceptibility to lung cancer. Int J Cancer 1998; 77: 516-521.

30 Lancaster JM, Brownlee HA, Bell DA, et al. Microsomal epoxide hydrolase polymorphism as a risk factor for ovarian cancer. Mol Carcinog 1996; 17: 160-162.

31 Spurdle AB, Purdie DM, Webb PM, et al. The microsomal epoxide hydrolase Tyr113His polymorphism: association with risk of ovarian cancer. Mol Carcinog 2001; 30: 71-78.

32 Sillanpaa P, Hirvonen A, Kataja V, et al. NAT2 slow acetylator genotype as an important modifier of breast cancer risk. Int $J$ Cancer 2005; 114: 579-584.

33 Cascorbi I, Roots I. Pitfalls in $\mathrm{N}$-acetyltransferase 2 genotyping. Pharmacogenetics 1999; 9: 123-127.

34 Vatsis KP, Weber WW, Bell DA, et al. Nomenclature for $\mathrm{N}$ acetyltransferases. Pharmacogenetics 1995; 5: 1-17.

35 Benhamou S, Reinikainen M, Bouchardy C, et al. Association between lung cancer and microsomal epoxide hydrolase genotypes. Cancer Res 1998; 58: 5291-5293.

36 Nielsen DM, Ehm MG, Weir BS. Detecting marker-disease association by testing for Hardy-Weinberg disequilibrium at a marker locus. Am J Hum Genet 1998; 63: 1531-1540.

37 Rothman KJ. No adjustments are needed for multiple comparisons. Epidemiology 1990; 1: 43-46. 